\title{
Validation of a diabetes risk score in identifying patients at risk of progression to abnormal glucose tolerance post partum
}

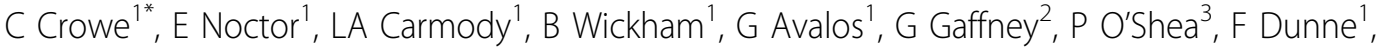 \\ ATLANTIC DIP Collaborators
}

From International Conference for Healthcare and Medical Students 2011

Dublin, Ireland. 4-5 November 2011

\section{Introduction}

FINDRISC (Finnish Diabetes Risk Score) is a risk assessment tool widely used for the prediction of the development of type 2 diabetes (T2DM), combining a questionnaire with simple anthropometric measurements to identify patients at risk of developing diabetes, with increasing score (0-26) signifying increased risk. A cut off score of 9 has previously been proposed (with drug-treated DM as the endpoint) with a positive predictive value (PPV) of 0.12 and negative predictive value (NPV) of 0.99 , area under receiver operating characteristic curve $(\mathrm{AuROC})=0.80$. It has been well validated in the general population.

\section{Methods}

We examined its use in predicting progression to pre-diabetes/diabetes in a cohort of Caucasian patients with a history of gestational diabetes mellitus (GDM). 116 women with a history of GDM underwent screening 1-5 years post-index pregnancy. Those with a history of persistent post-partum dysglycaemia had fasting glucose levels taken, while others underwent a 75g OGTT.

\section{Results}

Of the 116 women with a history of GDM, 83 showed normal glucose tolerance (NGT) post-partum (71.6\%). 22 patients had abnormal OGTT at 12 weeks (18.9\%). A further 11 patients $(9.5 \%)$ had pre-diabetes/diabetes at rescreening. The FINDRISC score was higher in patients with pre-diabetes/diabetes than those with NGT post partum (mean score $13.6+/-4.1$ vs. $11.0+/-3.7, \mathrm{p}<0.01$ ). For a cut-off score of 9, PPV was 0.30, NPV was 0.79,

'Department of Medicine, University Hospital Galway and National University of Ireland, Galway, Ireland

Full list of author information is available at the end of the article
AuROC $=0.69$, comparable with published data in the general population.

\section{Conclusions}

This study shows the validity of an inexpensive, convenient risk score in helping to determine which patients may need more frequent screening post GDM.

\section{Author details}

'Department of Medicine, University Hospital Galway and National University of Ireland, Galway, Ireland. 'Department of Obstetrics and Gynaecology, University Hospital Galway, Ireland. ${ }^{3}$ Department of Clinical Biochemistry, University Hospital Galway, Ireland.

Published: 9 July 2012

doi:10.1186/1753-6561-6-S4-036

Cite this article as: Crowe et al: Validation of a diabetes risk score in identifying patients at risk of progression to abnormal glucose tolerance post partum. BMC Proceedings 2012 6(Suppl 4):O36.

Submit your next manuscript to BioMed Central and take full advantage of:

- Convenient online submission

- Thorough peer review

- No space constraints or color figure charges

- Immediate publication on acceptance

- Inclusion in PubMed, CAS, Scopus and Google Scholar

- Research which is freely available for redistribution

Submit your manuscript at www.biomedcentral.com/submit

\section{Biomed Central}

(c) 2012 Crowe et al; licensee BioMed Central Ltd. This is an Open Access article distributed under the terms of the Creative Commons Attribution License (http://creativecommons.org/licenses/by/2.0), which permits unrestricted use, distribution, and reproduction in any medium, provided the original work is properly cited. 